\title{
Placing nasogastric tubes in stroke patients with dysphagia: efficiency and tolerability of the reflex placement
}

\author{
R Dziewas, M Schilling, C Konrad, F Stögbauer and P Lüdemann
}

J Neurol Neurosurg Psychiatry 2003;74:1429-1431

Temporary dysphagia affects up to $50 \%$ of stroke patients in the acute stage of their illness and often necessitates tube feeding. In these patients, the placing of nasogastric tubes is often difficult or impossible. This study evaluated the efficiency and tolerability of a previously described new method for tube placing, which utilises the induction of the swallowing reflex and has therefore been called "reflex placement". In 14 of 16 patients in whom the conventional approach failed, the new method was successful. A comparison of the cardiovascular responses to both methods in another 12 patients revealed significantly smaller increases in heart rate and systolic blood pressure during application of the new method. We therefore suggest the use of reflex placement in patients who have suffered a stroke and need tube feeding due to dysphagia.

$\mathrm{S}$ wallowing abnormalities (dysphagia) are a common functional impairment of acute stroke, affecting as many as $50 \%$ of all patients. ${ }^{1-11}$ Most regain a normal swallowing function within 1 week after onset of the disease, although dysphagia persists in a small number of subjects. ${ }^{14}$ To facilitate an enteral diet and to reduce the risk of aspiration pneumonia, ${ }^{12}$ dysphagic stroke patients often have to be fed for a few days by nasogastric tubes (NGT). However, placing NGT in stroke patients is often difficult, as the required co-operation of the patients is frequently impaired because of a reduced state of consciousness, aphasia, lingual uncoordination, or buccofacial apraxia. Therefore we developed a simple method for placing NGTs by inducing the swallowing reflex ("reflex placement"), which is independent of the patient's ability to co-operate. ${ }^{13}$

In the present study, we assessed the efficiency of the reflex placement in patients in whom the conventional method had failed, thereby expanding on a previous pilot study. ${ }^{13}$ We then investigated the tolerability of the reflex placement by comparing the cardiovascular responses between both methods.

\section{PATIENTS AND METHODS \\ Patients}

All patients treated in our stroke unit within a 10 month period who needed tube feeding were included in the study. The study includes patients already published in a preliminary report. ${ }^{13}$ Swallowing was assessed with the $50 \mathrm{ml}$ water swallowing test. ${ }^{14}$ Coughing during or for 1 min after completion of the test or the presence of a post-swallow wet, hoarse voice quality were scored as abnormal and indicated a need for temporary tube feeding. In all patients the severity of the stroke was measured with the National Institute of Health Stroke Scale (NIH scale). The study was approved by the local ethics committee, which waived the need for informed consent.

\section{Reflex placement of NGTs}

A thin catheter was inserted through the nostril with its tip being placed in the oropharynx. The NGT was placed through the other nostril in approximately the same position. The swallowing reflex was induced by bolus injection of $0.5-2.0 \mathrm{ml}$ of distilled water through the thin catheter. ${ }^{15}$ At the onset of swallowing, which was identified by observation of the characteristic upward laryngeal movement, the NGT was moved forward.

\section{Study design}

For evaluating the efficiency of the new method, patients in whom a NGT had to be placed were divided into two groups. The control group comprised those patients in whom the conventional approach was successful. Patients in whom the conventional approach failed were allocated to the study group. At least four attempts and the use of known facilitating measures such as increasing the rigidity of the tube by refrigeration and tilting the patient's head forward were required before the application of the new method was allowed. ${ }^{16}$

For evaluating the tolerability of the new method, changes in heart rate, systolic arterial blood pressure and oxygen saturation in response to either method of tube placement were scored in a further group of patients needing tube feeding because of dysphagia. For this investigation, we took into account only patients for whom, because of selfextubation or tube obstruction, at least two NGT placements within $48 \mathrm{~h}$ were necessary, and therefore both methods could be studied in close succession. In half the patients, the conventional method was performed first, and in the other half the new method was used. The number of attempts until achievement of correct placement was scored. The presence of concomitant medication modulating blood pressure or heart rate was noted.

\section{Statistics}

Unpaired data was compared with the Mann-Whitney $U$ test, paired data was analysed with the Wilcoxon matched pair test. The level of significance was set at $\mathrm{p}<0.05$.

\section{RESULTS}

During the study period, 386 patients were treated in our stroke unit. Sixteen (15.4\%) of 104 patients who needed tube feeding because of disturbed swallowing were selected for the study group. The mean age and severity of stroke did not differ significantly between the two groups (table 1). Clinically, ten patients in the study group had severe aphasia and buccofacial apraxia because of infarction of the left middle cerebral artery (MCA) or left sided intracerebral haemorrhage $(\mathrm{ICH})$. Eight patients, two with infarction of the left MCA, three with infarction of the right MCA, and three with brainstem infarction, had a markedly reduced

Abbreviations: $\mathrm{ICH}$, intracerebral haemorrhage; $\mathrm{MCA}$, middle cerebral artery; NGT, nasogastric tube 
Table 1 Characteristics of stroke patients

\begin{tabular}{lll}
\hline & $\begin{array}{l}\text { Conventional } \\
\text { placement }(\mathbf{n}=88)\end{array}$ & $\begin{array}{l}\text { Reflex placement } \\
(\mathbf{n}=16)\end{array}$ \\
\hline $\begin{array}{l}\text { Age (years) } \\
\text { Lesion location }\end{array}$ & $68.9(1.5)$ & $67.9(14.4)$ \\
Left MCA & 40 & 9 \\
Right MCA & 24 & 3 \\
Left MCA \& ACA & 4 & 0 \\
Right MCA \& ACA & 1 & 0 \\
Left ICH & 2 & 1 \\
Right ICH & 3 & 0 \\
Brainstem & 14 & 3 \\
NIH Stroke Scale (points) & $13.7(6.2)$ & $14.5(5.8)$ \\
\hline
\end{tabular}

Numbers are expressed as mean (SD).

$A C A$, anterior cerebral artery; $I C B$, intracerebral hemorrhage; $M C A$,

middle cerebral artery; NIH, National Institute of Health

level of consciousness. In these patients, the conventional approach repeatedly resulted in tracheal positioning of the tube or its coiling in the mouth. By using the swallowing reflex, the tube was successfully placed in 14 of 16 patients $(87.5 \%)$. The two failures occurred in patients with a left MCA infarction and a brainstem infarction respectively, in whom the swallowing reflex could not be provoked.

Twelve patients (mean age 69.0 (5.9); mean NIH 15.9 (4.7)) were included in the second part of the study. Five had suffered an infarction of the left, and four of the right MCA. One patient each suffered an infarction of left MCA and ACA, a brainstem infarction, or a right sided ICH. During both placements, a continuous infusion of urapidil was given to two patients and verapimil to one. As stated above, the conventional method was used first in six patients, while in the other six patients the NGT was initially placed using the new method.

The new method enabled tube placement in nine patients in the first and in three patients in the second attempt, making an average of 1.3 trials, whereas the conventional approach was successful only after an average of 2.2 trials $(\mathrm{p}<0.01$; table 2$)$. This difference was mainly due to repetitive gagging and insufficient voluntary swallowing of the NGT during the conventional approach. The baseline parameters were similar for both groups. In both the conventional and the new method, placement resulted in a significant increase in heart rate and systolic arterial blood pressure, whereas oxygen saturation remained stable. However, these haemodynamic changes were significantly larger for the conventional than for the new method (average maximum systolic arterial blood pressure of $176 \mathrm{mmHg} v$ $154 \mathrm{mmHg}$; average maximum heart rate of 108 beats/min $v$ 94 beats/min, respectively) (table 2 ).

Table 2 Number of trials, vegetative and oxygen saturation changes during conventional and reflex placement of nasogastric tubes

\begin{tabular}{|c|c|c|c|}
\hline & $\begin{array}{l}\text { Conventional } \\
\text { placement }\end{array}$ & $\begin{array}{l}\text { Reflex } \\
\text { placement }\end{array}$ & p value \\
\hline Number of trials & $2.2(0.8)$ & $1.3(0.5)$ & $<0.01$ \\
\hline Baseline $\mathrm{BP}_{\text {sys }}(\mathrm{mm} \mathrm{Hg})$ & $141(17)$ & $145(28)$ & NS \\
\hline NGT BP $P_{\text {sys }}(\mathrm{mm} \mathrm{Hg})$ & $176(16)^{*}$ & $156(28)^{*}$ & $<0.01$ \\
\hline Baseline HR (beats/min) & $85(13)$ & $82(15)$ & NS \\
\hline NGT HR (beats/min) & $108(16)^{*}$ & $94(16)^{*}$ & $<0.01$ \\
\hline Baseline $\mathrm{SaO}_{2}(\%)$ & 97 (1) & 97 (1) & NS \\
\hline NGT $\mathrm{SaO}_{2}(\%)$ & $96(2)$ & 97 (1) & NS \\
\hline
\end{tabular}

Numbers are expressed as mean (standard deviation) $\mathrm{NS}$, not significant; $\mathrm{BP}_{\text {sys, }}$ systolic blood pressure; $\mathrm{NGT} \mathrm{BP}_{\text {sys, }}$ systolic blood pressure during placement of a nasogastric tube; $H R$, heart rate $\mathrm{SaO}_{2}$, oxygen saturation.

${ }^{*} \mathrm{p}<0.01$ for the comparison of baseline and intervention parameters.

\section{DISCUSSION}

Our study confirms that the placing of NGT by inducing the swallowing reflex is a useful alternative if the conventional method fails. In 14 of 16 patients $(87.5 \%)$ in whom the conventional approach repeatedly resulted in tracheal positioning of the tube or its coiling in the mouth, the new method was successful. Equally encouraging results using the reflex placement were achieved by Inoue et al ${ }^{17}$, who reported a success rate of $82.6 \%$ in a more elderly collective of stroke patients (mean age 86.7 years).

A comparative study of the cardiovascular responses to both methods showed that the reflex placement was less distressing for the patients, leading to a significantly smaller increase in heart rate and systolic blood pressure. The main reason for this seems to be the fact that with this method significantly fewer attempts were needed $(1.3 v 2.2)$ until correct placement of the tube was achieved.

The main drawback of our procedure is that it may be of only limited use in patients with brainstem infarction as they are likely to lack a sufficient swallowing reflex.

Apart from the argument of increasing the patients' comfort, the avoidance of intermittent peaks of intracranial pressure induced for example by coughing or gagging constitutes a basic principle of care in patients with space occupying brain lesions. ${ }^{18}$ Therefore, even if the new method requires a larger effort by necessitating the co-operation of two medical staff members, we recommend its use in patients who have suffered a stroke and need tube feeding due to dysphagia.

\section{ACKNOWLEDGEMENTS}

We are grateful to Anthony $\mathrm{T}$ Herdman, PhD, Rotman Research Institute, Toronto, Canada, for expert help with the English language.

\section{Authors' affiliations}

R Dziewas, M Schilling, C Konrad, F Stögbauer, P Lüdemann,

Department of Neurology, University of Münster, Albert-Schweitzer-Str. 33, D-48129 Münster, Germany

Competing interest: none declared

Correspondence to: DrR Dziewas, Department of Neurology, University Hospital Münster, Albert-Schweitzer-Strasse 33, 48129 Münster, Germany; dziewas@uni-muenster.de

\section{REFERENCES}

1 Gordon C, Langton-Hewer R, Wade DT. Dysphagia in acute stroke. BMJ 1987;295:411-14.

2 Horner J, Massey EW, Ricki JE, et al. Silent aspiration following stroke. Neurology 1988;38:317-19.

3 Horner J, Massey EW, Riski JE, et al. Aspiration following a stroke: clinical correlates and outcome. Neurology 1988;38:1359-62.

4 Barer DH. The natural history and functional consequences of dysphagia after hemispheric stroke. J Neurol Neurosurg Psychiatry 1989;52:236-41.

5 Horner J, Brazer SR, Massey EW. Aspiration in bilateral stroke patients: a validation study. Neurology 1993:43:430-3.

6 Robbins J, Levine RL, Master A, et al. Swallowing after unilateral stroke of the cerebral cortex. Arch Phys Med Rehabil 1993;74:1295-1300.

7 Kidd D, Lawson J, Nesbitt R, et al. Aspiration in acute stroke: a clinical study with videofluoroscopy. Q J Med 1993:86:825-9.

8 Holas MA, DePippo KL, Reding MJ. Aspiration and relative risk of medical complications following stroke. Arch Neurol 1994;51:1051-3.

9 Smithard D, O'Neill P, Park C, et al. Complications and outcome after acute stroke: does dysphagia matter? Stroke 1996;27:1200-4.

10 Smithard D, O'Neill PA, England RE, et al. The natural history of dysphagia following a stroke. Dysphagia 1997;12:188-93.

11 Mann G, Dip PG, Hankey GJ, et al. Swallowing function after stroke prognosis and prognostic factors at 6 months. Stroke 1999:30:744-8.

12 Nakajoh K, Nakagawa T, Sekizawa K, et al. Relation between incidence of pneumoniae and protective reflexes in post-stroke patients with oral or tube feeding. J Int Med 2000;247:39-42.

13 Dziewas R, Lüdemann P, Konrad C, et al. Simple method for placing nasogastric tubes in patients with dysphagia. Lancet 2001;358:725-6.

14 Gottlieb D, Kipnis M, Sister E, et al. Validation of the $50 \mathrm{ml}$ drinking test for evaluation of post-stroke dysphagia. Disabil Rehabil 1996; 18:529-32. 
15 Teramato $S$, Matsuse T, Fukuchi $Y$, et al Simple two-step swallowing provocation test for elderly patients with aspiration pneumonia. Lancet 1999;353:1243. 16 Dyer I, Ashton WB. How to pass a nasogastric tube. Br J Hosp Med 1991:45:45-6.
17 Inoue K, Takano H, Yamada T, et al. Nasogastric tubes in patients with dysphagia. Lancet 2002;359:81.

18 Marik P, Chen K, Varon J, et al. Management of increased intracranial pressure: a review for clinicians. J Emerg Med 1999;17:711-19.

\section{NEUROLOGICAL PICTURE}

\section{Intracranial aneurysm: seen and unseen}

A 46 year old female with left sided frontal headache and a partial left third nerve palsy underwent magnetic resonance angiography (MRA) followed by digital subtraction angiography (DSA). MRA identified a left posterior communicating artery aneurysm (fig 1). DSA confirmed a $7 \mathrm{~mm}$ aneurysm on the left and also revealed a $3 \mathrm{~mm}$ right posterior communicating aneurysm (fig 2), which was not evident using MRA.

Detection rates using non-invasive imaging methods are significantly poorer for smaller $(<5 \mathrm{~mm})$ aneurysms. $^{1}$ Aneurysm size is an important factor in aneurysm detection, with studies of MRA consistently indicating sensitivity of $>95 \%$ for aneurysms $>6 \mathrm{~mm}$ diameter. For aneurysms $<5 \mathrm{~mm}$ detection rates as low as 56\% have been reported. ${ }^{2}$ With standard time of flight MRA technique flow related artefacts may obscure some of the anatomical detail.

Despite the known limitations clinicians often request MRA to screen for intracranial aneurysms, aware that smaller aneurysms will not be demonstrated. ${ }^{3}$ This case supports the view that clinically significant aneurysms will be detected by MRA, but smaller asymptomatic lesions will be missed. It gives a convenient comparison of MRA visible and invisible aneurysm dimensions.
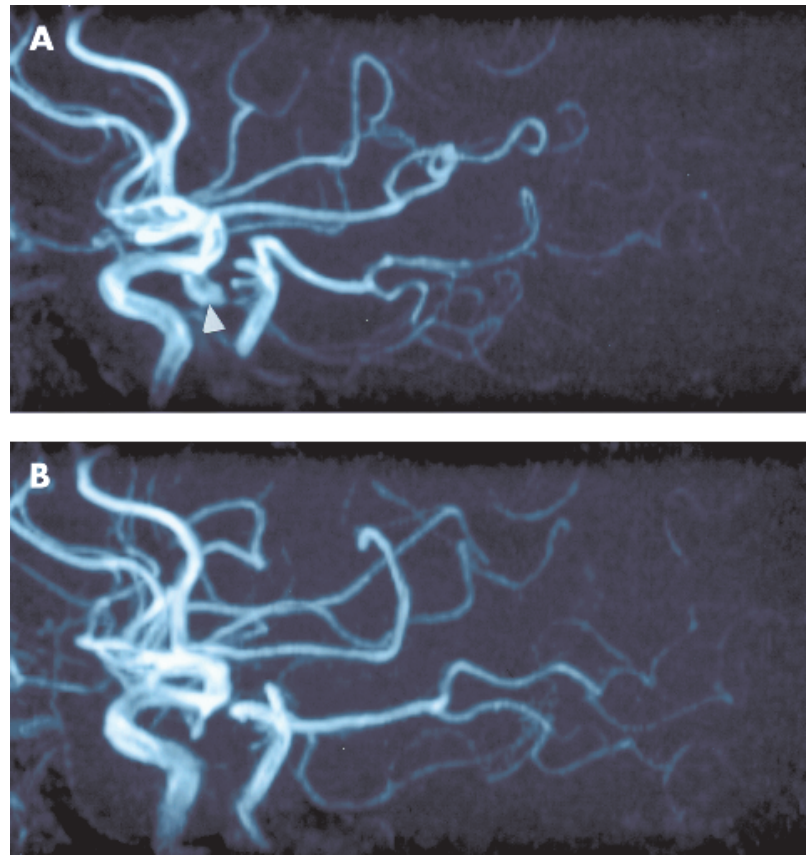

Figure 1 (A) Time of flight MRA of the left carotid artery showing a left posterior communicating aneurysm. (B) Normal right side.

J K Kraft

Division of Radiology, The James Cook University Hospital, Marton Road, Middlesbrough TS4 3BW, UK

N Bradey, P K Newman

Neuroscience Division, Middlesbrough General Hospital, Ayresome Green Lane, Middlesbrough TS5 5AZ, UK

Correspondence to: Dr P K Newman; peter.newman@stees.nhs.uk
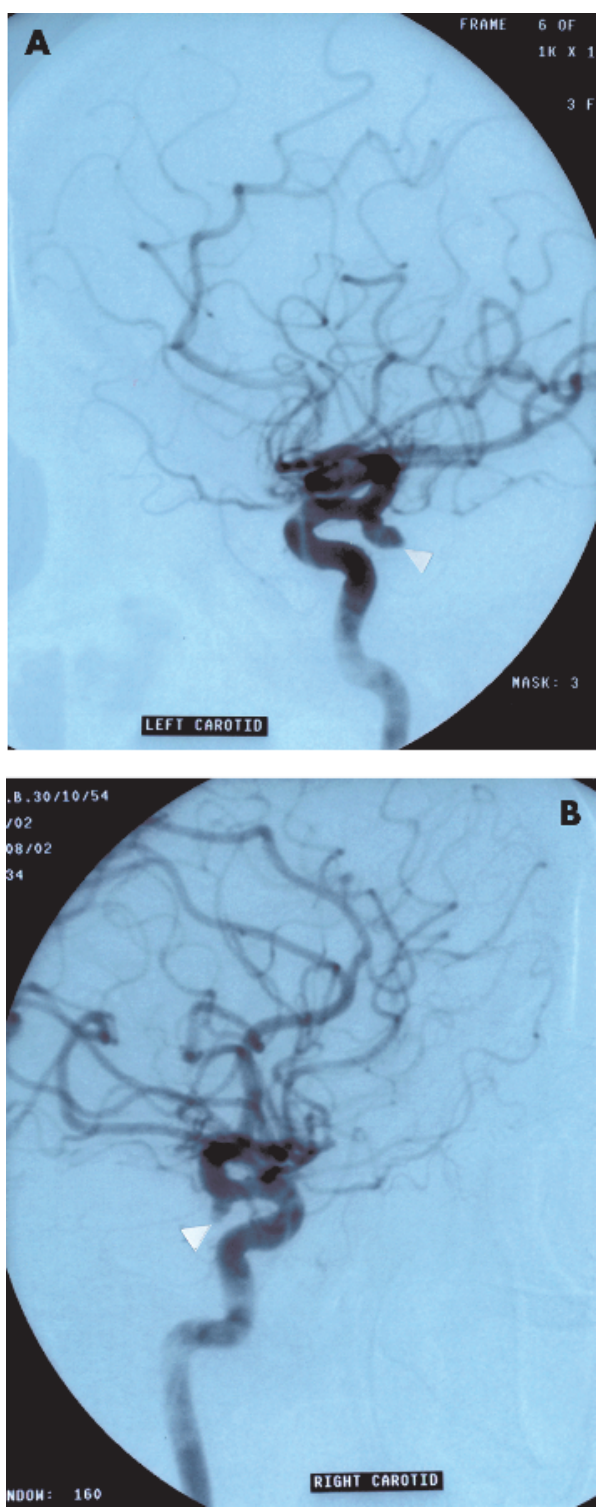

Figure 2 (A) Digital subtraction angiogram of the left carotid artery showing a $7 \mathrm{~mm}$ posterior communicating aneurysm. (B) Digital subtraction angiogram of the right carotid artery showing a $3 \mathrm{~mm}$ posterior communicating aneurysm.

\section{References}

1 Wardlaw JM, White PM. The detection and management of unruptured intracranial aneurysms. Brain 2000;123:205-21.

2 Korogi Y, Takahashi M, Mabuchi N, et al. Intracranial aneurysms: diagnostic accuracy of MR angiography with evaluation of maximum intensity projection and source images. Radiology 1996;199:199-207.

3 Kojima M, Nagasawa S, Lee YE, et al. Asymptomatic familial cerebral aneurysms. Neurosurgery 1998;43:776-81. 